\title{
Commentary on two reviews of anterior composite restorations
}

\section{Abstracted from}

Demarco FF, Collares K, Coelho-de-Souza FH, Correa MB, Cenci MS, Moraes RR, Opdam NJ.

Anterior composite restorations: A systematic review on long-term survival and reasons for failure. Dent Mater 2015; 31: 1214-1224. pii S0109-5641(15)00214-6. doi: 10.1016/j.dental.2015.07.005. [Epub ahead of print] Review. PubMed PMID: 26303655

\section{Heintze SD, Rousson V, Hickel R.}

Clinical effectiveness of direct anterior restoration - a meta-analysis. Dent Mater 2015; 31: 481-495. doi: 10.1016/j.dental.2015.05.015. Epub 2015 Mar 13. PubMed PMID: 257731887
Address for correspondence:

Flávio F. Demarco, Graduate Program in Dentistry, Federal University of Pelotas Rua Goncalves Chaves 457, Room 506 96015-560, Pelotas-RS, Brazil. E-mail: flavio.demarco@pq.cnpq.br; ffdemarco@gmail.com
Heintze SD, Ivolar Vivadent, Bendererstr. 2, 9494 Schaan, Leichtenstein E-mail: siegward.heintze@ivoclarvivadent.com

\begin{tabular}{|l|l|}
\hline Question: \\
$\begin{array}{l}\text { What is the longevity } \\
\text { of anterior composite } \\
\text { restorations? }\end{array}$ & $\begin{array}{l}\text { What is the clinical } \\
\text { effectiveness } \\
\text { (durability and } \\
\text { longevity) of } \\
\text { anterior composite } \\
\text { restorations? }\end{array}$ \\
\hline
\end{tabular}

Data sources

Medline/PubMed, SciVerse, Scopus and the Cochrane Central Register of Controlled Trials databases without restriction of date or language.

\section{Study selection}

Longitudinal prospective or retrospective clinical trials evaluating clinical survival of direct restorations in anterior permanent teeth placed with visible light-cured composite resin were considered.

SCOPUS and Pubmed (1966December 2012) without restriction to language.

Prospective clinical trials evaluating clinical survival of class III/IV direct restorations in permanent teeth placed with composite resin, polyacid-modified resin composite (composer) or resin-modified glass-ionomer cements were considered.

Data extraction and synthesis

Two reviewers independently abstracted data and a narrative synthesis was presented.
Type of cavity, type of enamel/ dentin conditioning, type of resin composite and operative procedure were abstracted and a meta-analysis of the longevity and durability (colour and texture, marginal integrity, anatomise form) was presented.

Two reviewers independently abstracted data and a narrative synthesis was presented.

\section{Results}

Seventeen studies were included with follow-up periods ranging from 3-17 years. Class III and IV restorations were considered by ten studies with five studies considering aesthetic restoration and two studies considering tooth wear restoration. Only seven studies were restricted to the evaluation of anterior direct restorations. A modified version of the United States Public Health Service (USPHS) criteria were the criteria most often used to evaluate restorations ( 12 studies). The total overall failure rate was $24.1 \%$ (439 restorations out of 1821), with individual study annual failure rates varying from 0 to $4.1 \%$ and survival rates from $53.4 \%$ to $100 \%$.

Twenty-one studies were included with follow up-periods ranging from 2-12 years. Class III and IV restorations $(2,300$ at baseline and 1,722 at last recall) were considered in 14 and seven studies respectively. The estimated median longevity afte ten years was $95 \%$ and $90 \%$ for Class III and IV respectively. The main reason for the replacement of Class IV restorations was bulk fractures, which occurred significantly more frequently with microfilled composite than with hybrid and macrofilled composite. Cavities adjacent to restorations were infrequent in most studies and accounted only for about $2.5 \%$ of all replacement restorations after ten years, irrespective of the cavity class.

\section{Conclusions}

Findings of the present review generally indicate a good clinical performance in the long-term (follow-up three+ years) for anterior composite resin restorations, with annual failure rates varying from 0 to $4.1 \%$. It seems that failure behaviour in anterior restorations is different from posterior teeth, with less secondary caries present and more restorations being replaced for other reasons such as aesthetic appearance. However, there is still room for well designed clinical trials to evaluate the longevity of anterior composite restorations and investigate the specific factors associated with failure.
The meta-analysis found the long-term clinical performance (two+ years) of Class III/IV composite resin restorations is generally good with a ten years median success of $95 \%$ and $90 \%$ respectively. Adhesive systems which allow for enamel etching with $37 \%$ phosphoric acid reduces the occurrence of marginal discolouration. Hybrid composite performs better than microfilled composite, compositor and glass ionomer cements. Bevelling of enamel is not necessary but adequate isolation is important for long lasting restorations. 
Table 1 - Comparison of two recent reviews on the clinical effectiveness of anterior restorations

Demarco et al. (2015)

\begin{tabular}{|c|c|c|}
\hline Last Date of Review & Dec 2014 & Dec 2012 \\
\hline Meets PRISMA Guidelines & Attempts & Does not attempt \\
\hline Number of Included Studies & 17 & 21 \\
\hline Types of Included Studies & Prospective and retrospective & Prospective \\
\hline $\begin{array}{l}\text { Inclusion } \\
\text { - Restorations } \\
\text { - Materials }\end{array}$ & $\begin{array}{l}\text { - III, IV, Veneers and Core Build } \\
\text { - Light-Curing Composite Resins }\end{array}$ & $\begin{array}{l}\text { - III, IV, Veneers and Core Build } \\
\text { - Light-Curing and Self-Curing Composite Resins, } \\
\text { Compomers and Glass lonomers }\end{array}$ \\
\hline Duration of Study (Years) & $3-17$ & $2-13$ \\
\hline Number of Restorations & $\begin{array}{l}1821 \\
\text { (Not clear if at baseline or at last follow-up) }\end{array}$ & $\begin{array}{l}2,300 \text { at baseline } \\
1,722 \text { at last recall }\end{array}$ \\
\hline Analysis of the Extracted Data & Qualitative Analysis & Meta-Analysis \\
\hline AFR (\%) & $0-4.1$ & $1.3-2.5$ * \\
\hline
\end{tabular}

${ }^{*}$ Calculated using data from Figure 9 of Heintze et $a l .{ }^{1}$ and the formula described by Demarco et al. ${ }^{2}$

\section{Commentary}

Two articles published in the Journal of Dental Materials on the longevity of anterior restorations were recently reviewed. ${ }^{1,2}$ Although the authors of both articles come to a similar conclusion, they arrive at it from different perspectives (see Table 1).

Demarco et al.'s qualitative analysis is a more comprehensive systematic review that falls short of meeting the PRISMA guidelines by not doing a risk of bias analysis, an assessment of the quality of the included studies and an assessment of the risk to publication bias. $^{3}$ On the other hand, the article by Heintze et al. does not even try to meet the PRISMA guidelines of a systematic review but is more a meta-analysis of some selected articles. Other differences are listed in Table 1.

Ideally, the clinical longevity of dental restorations is evaluated using a Kaplan-Meier survival analysis. This type of time-to-event data analysis follows a restoration through time and records, exactly when the failure occurred, and accounts for cases that were lost to follow-up (censored data). Intuitively, restorative failure rates are not linear but follow a geometric curve, where instantaneous rate of failure (referred to as the hazard rate) gets progressively greater over time. In other words, the annual rate of failure (AFR) is not constant but typically becomes progressively higher in the later years of the study.

Demarco et al.'s review circumvents this problem by using the AFR to assess the clinical durability of the restoration over time. The AFR is an engineering metric typically used to compare the longer-term durability of two or more objects. ${ }^{4}$ The problem with using the AFR as a stand-alone metric is that it is based on the incorrect assumption that the AFR is constant over time (linear). An AFR alone, without any comparison, offers limited value for clinical decision-making. For example, if Demarco et al. reported that Class IV restorations had an AFR of $4 \%$, and Class III restorations had an AFR of $2 \%$, then the ratio of these two AFRs implies that Class IV restorations are twice as likely to fail (hazard ratio) as Class III restorations are, without specifying any one-year failure rate of either restoration.

Another problem with Demarco et al.'s analysis is that there is no discussion about how censored data was accounted for. Not considering censored data can bias the result, often in a more favourable direction. For example, from the van Dijken \& Pallesen study (2010), ${ }^{5}$ Demarco et al. calculated the success rate and AFR to be $74.4 \%$ and $2 \%$, respectively. This calculation was based on 43 restorations at the start of the study. However, the study reported that three restorations were lost to follow-up. Demarco et al.'s calculation assumes that those three lost restorations were all successful, without knowing this for sure. If we were to assume that the three restorations were actually failures, the success rate would drop to $67 \%$ and the AFR would rise to $2.8 \%$.

Another limitation of Demarco et al.'s systematic review is that the risk of publication bias was not assessed. It is possible that publication bias may have played a role in this review, as many dental studies are supported by manufacturers with commercial interest. Industrysponsored research is more likely to report favourable outcomes compared to research not directly funded by industry. ${ }^{6}$

Despite the limitations of both reviews, they generally conclude that anterior composite restorations typically perform comparably to posterior composite resins in the short-to-moderate time frame.

\section{Ben Balevi}

University of British Columbia, Vancouver, Canada

1. Heintze SD, Rousson V, Hickel R. Clinical effectiveness of direct anterior restoration - a meta-analysis. Dent Mater 2015; 31:481-495. doi: 10.1016/j.dental.2015.05.005.

2. Demarco FF, Collares K, Coelho-de-Souza FH, et al. Anterior composite restorations: A systematic review on long-term survival and reasons for failure. Dent Mater 2015; 31: 1214-1224. pii: S0109-5641(15)00214-6. doi: 10.1016/j.dental.2015.07.005. [Epub ahead of print] Review. PubMed PMID: 26303655.

3. Liberati A, Altman DG, Tetzlaff J, et al. The PRISMA statement for reporting systematic reviews and meta-analyses of studies that evaluate healthcare interventions: explanation and elaboration. BMI 2009; 339: b2700. doi: 10.1136/bmj.b2700

4. Elerath JG. AFR: problems of definition, calculation and measurement in a commercial environment. Reliability and Maintainability Symposium, 2000 (Annual Proceedings) p. 71-76 doi: 10.1109/RAMS.2000.816286.

5. van Dijken JW, Pallesen U. Fracture frequency and longevity of fractured resin composite, polyacid-modified resin composite, and resin-modified glass ionomer cement class IV restorations: an up to 14 years of follow-up. Clin Oral Investig 2010; 14: $217-222$.

6. Balevi B. Industry sponsored research may report more favourable outcomes. Evid Based Dent 2011; 12: 5-6. doi: 10.1038/sj.ebd.6400769.

Evidence-Based Dentistry (2016) 17, 90-91. doi:10.1038/sj.ebd.6401192 